\title{
Polycaprolactone nanofibers as an adjuvant strategy for Tamoxifen release and their cytotoxicity on breast cancer cells
}

\author{
Ana D Pinzón-García ${ }^{1}$, Ruben Sinisterra ${ }^{1}$, Maria Cortes $^{2}{ }^{2}$ Fredy Mesa $^{\text {Corresp., }}{ }^{3}$, Sandra Ramirez Clavijo ${ }^{3}$ \\ ${ }^{1}$ Chemistry Department, Instituto de Ciências Exatas, Universidade Federal de Minas Gerais, Belo Horizonte, Brazil \\ 2 Restorative Dentistry Department, Faculty of Dentistry, Universidade Federal de Minas Gerais, Belo Horizonte, Brazil \\ 3 Faculty of Natural Sciences, Department of Biology, Universidad del Rosario, Bogotá, Colombia \\ Corresponding Author: Fredy Mesa \\ Email address: fredy.mesa@urosario.edu.co
}

Breast cancer is the second leading cause of death in women, and tamoxifen citrate (TMX) is accepted widely for the treatment of hormone receptor-positive breast cancers. Several local drug-delivery systems, including nanofibers, have been developed for antitumor treatment. Nanofibers are biomaterials that mimic the natural extracellular matrix, and they have been used as controlled release devices because they enable highly efficient drug loading. The purpose of the present study was to develop polycaprolactone (PCL) nanofibers incorporating TMX for use in the treatment of breast tumors. Pristine PCL and PCL-TMX nanofibers were produced by electrospinning and characterized physiochemically using different techniques. In addition, an in vitro study of TMX release from the nanofibers was performed. The PCL-TMX nanofibers showed sustained TMX release up to $14 \mathrm{~h}$, releasing $100 \%$ of the TMX. The Resazurin reduction assay was used to evaluate the TMX cytotoxicity on MCF-7 breast cancer cell line and PBMCs human. The PCL-TMX nanofiber was cytotoxic toPBMCs and MCF-7. Based on these results, the PCL-TMX nanofibers developed have potential as an alternative for local chronic TMX use for breast cancer treatment, however tissue tests must be done. 


\title{
1 Polycaprolactone nanofibers as an adjuvant strategy
}

2 for Tamoxifen release and their cytotoxicity on breast

3 cancer cells

4

5

6

7

8

\author{
A. D. Pinzón-García ${ }^{1}$, R. D. Sinisterra ${ }^{1}$, M. E. Cortés ${ }^{2}, F$. Mesa ${ }^{3, £}$, S. Ramírez-Clavijo ${ }^{3, *}$ \\ ${ }^{1}$ Chemistry Department, Instituto de Ciências Exatas, Universidade Federal de Minas Gerais, \\ Av. Presidente Antônio Carlos 6627, Belo Horizonte, MG, CEP 31270901, Brazil \\ ${ }^{2}$ Restorative Dentistry Department, Faculty of Dentistry, Universidade Federal de Minas Gerais, \\ Av. Presidente Antônio Carlos 6627, Belo Horizonte, MG, CEP 31270901, Brazil \\ ${ }^{3}$ Universidad del Rosario, Faculty of Natural Sciences, Department of Biology, Carrera 24 \# \\ 63C-69, Bogotá D.C., 111221, Colombia \\ Corresponding Author: \\ F. Mesa ${ }^{\mathfrak{f}}$ \\ S. Ramirez-Clavijo* \\ Email address: fredy.mesa@urosario.edu.co; sandra.ramirez@urosario.edu.co
}

\section{Abstract}

Breast cancer is the second leading cause of death in women, and tamoxifen citrate (TMX) is accepted widely for the treatment of hormone receptor-positive breast cancers. Several local drugdelivery systems, including nanofibers, have been developed for antitumor treatment. Nanofibers are biomaterials that mimic the natural extracellular matrix, and they have been used as controlled release devices because they enable highly efficient drug loading. The purpose of the present study was to develop polycaprolactone (PCL) nanofibers incorporating TMX for use in the treatment of breast tumors. Pristine PCL and PCL-TMX nanofibers were produced by electrospinning and characterized physiochemically using different techniques. In addition, an in vitro study of TMX release from the nanofibers was performed. The PCL-TMX nanofibers showed sustained TMX release up to $14 \mathrm{~h}$, releasing $100 \%$ of the TMX. The Resazurin reduction assay was used to evaluate the TMX cytotoxicity on MCF-7 breast cancer cell line and PBMCs human. The PCL-TMX nanofiber was cytotoxic to PBMCs and MCF-7. Based on these results, the PCL-TMX nanofibers developed have potential as an alternative for local chronic TMX use for breast cancer treatment, however tissue tests must be done.

\section{Introduction}

Breast cancer is the second leading cause of death in women, after lung cancer ("International Agency for Research on Cancer," 2018). Treatment strategies for this disease include surgery, radiation therapy, chemotherapy, hormonal therapy, and targeted therapy, often applied in 
40

41

42

43

44

45

46

47

48

49

50

51

52

53

54

55

56

57

58

59

60

61

62

63

64

65

66

67

68

69

70

71

72

73

74

75

76

77

78

79

combination. Endocrine therapy is the treatment of choice for patients with hormone receptorpositive $(\mathrm{HR}+)$ breast cancer.

Breast cancer subtypes are defined by the expression of estrogen (ER) and progesterone (PR) receptors and the status of the HER-2 gene, which may be amplified. Breast cancer cell lines with molecular profiles similar to those of tumors are used to evaluate the effects of anticancer drugs in vitro. The MCF-7 cell line derives from the pleural effusion of a patient with breast adenocarcinoma and represents the luminal A breast cancer subtype because it has the same molecular profile (ER+, PR+, normal HER-2 status). The use of anti-ER drugs, such as tamoxifen $(\mathrm{TMX})$, for the treatment of HR+ $(\mathrm{ER}+$ and $\mathrm{PR}+)$ breast cancers is widely accepted (Johnston et al., 2016).

TMX, also known as 4-hydroxytamoxifen, is a nonsteroidal compound that selectively modulates the ER with antagonistic or agonist action, depending on the organ on which it acts (Salami \& Karami-Tehrani, 2003). It is an agonist in the liver, uterus, and bones, and an antagonist in the brain and mammary glands and vasomotor symptoms (Sestak et al., 2006). TMX has been used to stop the proliferation and inducing apoptosis of breast tumor cells through its anti-ER action (Mandlekar \& Kong, 2001; Salami \& Karami-Tehrani, 2003).

TMX has cytostatic and cytotoxic properties in the MCF-7 breast cancer cell line, not only stopping proliferation and inducing apoptosis, but also inducing differentiation and reducing cholesterol synthesis (Kedjouar et al., 2004; Medina, Favre \& Poirot, 2004); it also modulates immunity in patients with breast cancer (Robinson et al., 1993; Behjati \& Frank, 2009). Compared with those of healthy controls, lymphocytes from women with breast cancer treated with TMX showed significantly reduced killer activity, associated with a decrease in the absolute number of CD4type lymphocytes, and a greater proliferation response in the presence of the concanavalin A mitogen (Rotstein et al., 1988; Robinson et al., 1993; Behjati \& Frank, 2009). TMX is also effective against Ebola virus (De Clercq, 2015) and human immunodeficiency virus (Laurence, Cooke \& Sikder, 1990) infections, and a recent review highlighted its benefits in the treatment of respiratory diseases, such as coronavirus disease pneumonia (Salman et al., 2020). TMX and its active metabolites have prolonged serum half-lives, and higher doses have not been associated with improved outcomes; lower dosages have not been tested adequately. Furthermore, it is established in the literature that chronic TMX use (for $\geq 5$ years) could reduce the risk of death from PR+ ER+ breast cancer (Salami \& Karami-Tehrani, 2003; Karn et al., 2010; Group (EBCTCG), 2011; Hong et al., 2016; Drăgănescu \& Carmocan, 2017) but when is used with potent inhibitors of CYP2D6 could be a risk of mortality (Donneyong et al., 2016).

It is well known that the nanometric scale devices used in current research for the prevention, treatment and diagnosis of diseases such as cancer are mostly natural or synthetic polymers. The 
80 desirable properties for these materials are biocompatibility, biodegradability, allowable 81 controlled release of active agents and similarity to the native extracellular matrix of human tissues 82 and cells (Venugopal, Zhang \& Ramakrishna, 2005; Caracciolo et al., 2011; Rogina, 2014; 83 Mochane et al., 2019). At the same time, local delivery systems have the advantage over systemic 84 therapy of continuous drug delivery at higher concentrations directly to target sites. The benefits 85 of these systems include improved patient compliance, the reduction of toxic effects and systemic 86 complications (Vyas, Sihorkar \& Mishra, 2000; Jain et al., 2008; Joshi et al., 2016), mimicking of 87 the natural extracellular matrix (ECM), and highly efficient drug loading for controlled release. 88 Nanoscale systems, such as those in which nanofibers are employed, may present a promising

89 90

91

92

93

94

95

96

97

98

99

100

101

102

103

104

105

106

107

108

109

110

111

112

113

114

115

116

117

118

119 opportunity for the efficient treatment of solid tumors.

Electrospun nanofibers are nanometric structures produced with synthetic or natural elements that create continuous filaments with a maximum diameter of $500 \mathrm{~nm}$ (Caracciolo et al., 2011). These materials are preferably biodegradable, to avoid the use of additional systems for their removal. The simplest use of nanofibers as a local drug release system involves the preparation of a polymer solution and its mixing with the drug, followed by nanofiber manufacture. Among numerous methods, electrospinning is becoming the main technique for the production of materials and carpets made of nano-polymer fibers and metal oxide (Barnes et al., 2007; Duque, Rodriguez \& Lopez, 2013; Rogina, 2014; Li et al., 2019). This method is simple, versatile, common, and economical (Rogina, 2014); it is performed in an electrospinning machine, which enables the use of different compounds and control of manufacturing parameters to determine the diameter, size, and porosity of the continuous nanofibers produced (Barnes et al., 2007). Various biopolymers have been used for tailored biomedical applications (Mochane et al., 2019).

Most nanometric-scale devices used in current research on the prevention, diagnosis, and treatment of diseases such as cancer are made of natural or synthetic polymers. Desirable properties for these materials are biocompatibility, biodegradability, capacity for controlled release of active agents, and similarity to the native ECM of human tissues and cells (Venugopal, Zhang \& Ramakrishna, 2005; Caracciolo et al., 2011; Rogina, 2014; Mochane et al., 2019). Poly ( $\varepsilon$-caprolactone) (PCL), a semi-crystalline aliphatic polyester, is the most commonly used synthetic polymer in medical applications because it biodegrades slowly and is biocompatible, given its similarity to natural tissue components such as collagen fibers and ECM and diameters of 50-500 nm (Venugopal, Zhang \& Ramakrishna, 2005; Barnes et al., 2007). PCL has good mechanical properties and thermal stability and is easy to process, compatible with hard and soft tissues, and accepted by the US Food and Drug Administration as a drug-delivery vehicle (Song et al., 2018). It has been used to develop devices for anticancer molecule release, an emerging promising alternative for cancer treatment (Monteiro et al., 2017).

In the present study, we developed PCL-pristine (P) and PCL-TMX nanofibers by electrospinning (Vitchuli et al., 2011) for local drug delivery to solid breast tumors. The nanofibers were 
120 characterized by scanning electron microscopy (SEM), Fourier-transform infrared spectroscopy 121 (FTIR) and attenuated total reflectance infrared spectroscopy (FTIR-ATR), X-ray powder 122 diffraction (XRD), thermal analysis, and contact angle measurement. Resazurin assays (Escobar, 123 2010) were used to assess their cytotoxic effects on MCF-7 cells and peripheral-blood mononuclear cells (PBMCs) from a healthy donor.

125

126

127

128

129

130

131

132

133

134

135

136

137

138

139

140

141

142

143

144

145

146

147

148

149

150

151

152

153

154

155

156

157

158

159

\section{Materials \& Methods}

\section{Materials}

PCL with molecular weights of 43,000-500,000 was purchased from Polysciences, Inc. (USA). TMX was supplied by Araujo Drug Supply S.A. (Brazil). Dichloromethane (DCM; 99.5\%) and methanol (MetOH; 99.8\%) were acquired from Vetec (Brazil). All reagents were of analytical grade and were used as received.

\section{Preparation of PCL Nanofiber Solutions and Electrospinning}

To prepare the PCL-P and PCL-TMX polymer solutions, $800 \mathrm{mg}$ PCL was dissolved in $10 \mathrm{~mL}$ $\mathrm{DCM} / \mathrm{MetOH}$ mixture $(50 \% / 50 \% \mathrm{v} / \mathrm{v})$ in each case. For the PCL-TMX solution, $15 \mathrm{mg}$ TMX was added. The solutions were agitated for $12 \mathrm{~h}$ at $25.0^{\circ} \mathrm{C}$ before use.

Each polymer solution was loaded into a $10-\mathrm{mL}$ standard plastic syringe fitted with a $27-\mathrm{G}$ blunted stainless-steel needle using a syringe pump (PHD 2000; Harvard Apparatus). The distance between the needle and the aluminum foil-wrapped collector was set at $15 \mathrm{~cm}$, and electrospinning was performed with a solution flow rate of $10 \mathrm{~mL} / \mathrm{h}$ and voltage of $20 \mathrm{kV}$ generated by a high-voltage power supply (Gamma High Voltage, USA). The resulting nanofibers were collected and stored for physicochemical characterization and microbiological and cytotoxicity testing.

\section{Physicochemical Characterization}

The conditions for the physicochemical characterization of the PCL and PCL-TMX nanofibers were similar and adjusted according to earlier studies (Ramírez-Agudelo et al., 2018; Dias et al., 2019).

Nanofiber morphology was analyzed by scanning electron microscopy (SEM) (FEG-Quanta 200; FEI) with an accelerating voltage of $20 \mathrm{kV}$. Before analysis of SEM images, each nanofiber sample was coated with a 5-nm-thick layer of gold using a sputter coater (MD20; Bal-Tec). The average nanofiber diameter was calculated from at least 100 measurements obtained with Image $J$ software (National Institutes of Health, Bethesda, USA). ATR was performed with a spectrophotometer (Spectrum 1SR; Perkin Elmer) equipped with a universal ATR sampling 
160

161

162

163

164

165

166

167

168

169

170

171

172

173

174

175

176

177

178

179

180

181

182

183

184

185

186

187

188

189

190

191

192

193

194

195

196

197

198

199

accessory and a diamond top plate. The FTIR-ATR spectra of the PCL-P and PCL-TMX nanofibers and TMX were obtained in the region of 4000-650 $\mathrm{cm}^{-1}$, with four scans obtained per sample at a resolution of $4 \mathrm{~cm}^{-1}$. The data were analyzed with the Spectrum software provided with the instrument (Perkin Elmer). The XRD patterns of the nanofibers were visualized using an $\mathrm{X}$-ray diffractometer (XRD-7000; Shimadzu) with $\mathrm{Cu} \mathrm{K \alpha} \lambda=0.154051$ radiations over a $2 \theta$ range of $4-60^{\circ}$ at a scanning speed of $2 \theta / \mathrm{min}$. Thermogravimetric and differential thermogravimetric analysis (TGA/DTG) was performed using a TGA Q5000 device (TA Instruments, USA) with sample heating at a rate of $10^{\circ} \mathrm{C} / \mathrm{min}$ from $25^{\circ} \mathrm{C}$ to $600^{\circ} \mathrm{C}$ and under an $\mathrm{N}_{2}$ flow rate of $50 \mathrm{~mL} / \mathrm{min}$. The TG curves represent the thermal degradation of the samples. The data were processed using the software supplied with the instrument (Universal Analysis 200; TA Instruments).

A contact angle measuring system (SEO Phoenix 300 Touch) was used to determine nanofiber wettability. The nanofibers were placed on a sample stand, and water was dropped onto their surfaces while a camera recorded an image. The Surfaceware 9 software was used to determine the average contact angle.

To evaluate the drug release profile of the PCL-TMX nanofibers (loaded at $25.5 \mu \mathrm{g}$ TMX/mg nanofiber approximately), approximately $15 \mathrm{mg}$ of nanofibers was cut into specimens $(15 \times 15$ $\mathrm{mm}$ ), which were placed into Eppendorf tubes. The tubes were then incubated at $37^{\circ} \mathrm{C}$ in $2 \mathrm{~mL}$ phosphate-buffered saline (PBS; pH 7.4) with $0.01 \%$ Sodium Dodecyl Sulfate (SDS) for increasing the TMX solubility, in a thermostatic shaker at $50 \mathrm{rpm}$. Samples $(2 \mathrm{~mL})$ were removed at $0.5,1,2,4,8,10,24,48,72,120$, and $144 \mathrm{~h}$ for the quantification of TMX release; after each analysis, the same volume of fresh PBS solution was added to the tube. The amount of TMX released was determined using an ultraviolet-visible (UV-vis) spectrophotometer (Multiskan Spectrum MCC/340; Thermo Scientific) at a wavelength of $365 \mathrm{~nm}$, based on a calibration curve $\left(R^{2}=0.99\right)$. Each sample was evaluated in triplicate.

\section{Cytotoxicity Testing}

For the in vitro analysis of cytotoxicity, the MCF-7 cell line was obtained from frozen vials of laboratory stock obtained from the ATCC (Manassas, VA, USA). The MCF-7 cells were grown in Dulbecco's modified Eagle medium (DMEM; Gibco) prepared with 1\% (v/v) antibiotic and antimycotic solution (ref. 15240062; Gibco) and supplemented with $10 \%$ fetal bovine serum (FBS; Gibco), in $75-\mathrm{cm}^{2}$ plastic bottles at $37^{\circ} \mathrm{C}$ in a $95 \%$ humid atmosphere with $5 \% \mathrm{CO}_{2}$.

To avoid the interference in the experiment of the action of the steroids present in the FBS, and of the weak estrogenic activity of the phenol red present in the DMEM, the cells were washed with PBS and then medium with 10\% carbon-stripped FBS (Sigma) and phenol red-free DMEM was added $48 \mathrm{~h}$ before incubation with the nanofibers. 
200 For peripheral-blood mononuclear cell (PBMCs) isolation, 10-mL peripheral blood samples were 201 obtained by venipuncture of the brachial vein from a healthy volunteer who had provided informed 202 consent. The blood was collected into tubes with heparin, and PBMCs were obtained using a Ficoll 203 gradient procedure (Rotstein et al., 1988). Briefly, the 10-mL tubes of blood were centrifuged at $2042000 \mathrm{rpm}$ for $5 \mathrm{~min}$, and the buffy coat was then removed with a sterile $2-\mathrm{mL}$ pipette. The buffy 205 coat $(2 \mathrm{~mL}$ ) was added gently to a $15-\mathrm{mL}$ tube with $2 \mathrm{~mL}$ Ficoll Histopaque-1077 (Sigma), which 206 was centrifuged without brake for $20 \mathrm{~min}$ at $2000 \mathrm{rpm}$. Then, the white layer was recovered with 207 a sterile $2-\mathrm{mL}$ pipette and placed in a new tube with $5 \mathrm{~mL}$ PBX 1X prepared from a 10X solution 208 (ref. 70011044; Gibco), which was centrifuged twice at $2500 \mathrm{rpm}$ for $5 \mathrm{~min}$. The cell pellet was 209 then recovered, gently resuspended, and placed in a new $15-\mathrm{mL}$ tube containing $5 \mathrm{~mL}$ PB-MAX 210 karyotyping medium (Invitrogen) with $100 \mu \mathrm{L}$ phytohemagglutinin (PHA) M (ref. 10576-015; 211 Gibco) and antibiotic and antimycotic solution (ref. 15240062; Gibco). The tube was stored at $21237^{\circ} \mathrm{C}$ and $5 \% \mathrm{CO}_{2}$ for $24 \mathrm{~h}$ before nanofibers treatment.

213

214 The cytotoxicity activity of PCL-TMX nanofibers were evaluated by an indirect contact resazurin 215 assay. The mean absorbance values obtained for all groups were distributed normally, and the 216 control group data were adjusted to $100 \%$ viability. Cytotoxicity was calculated based on cell 217 viability relative to this group: none, $>90 \%$; slight, $60-90 \%$; moderate, $30-59 \%$; and severe, $<30 \%$ 218 (Basak et al., 2016). This test indicates the number of viable cells and the level of metabolic activity 219 in a sample. Resazurin, a blue dye, is metabolized by mitochondrial enzymes in cells, which 220 transforms it into fluorescent pink resorufin, which the cells release into the culture medium. 221 Treatments can be monitored by taking several measurements of the same group of cells, as 222 resazurin is not toxic. Plates were removed from the incubator for a short time (5-10 $\mathrm{min})$ to take 223 measurements, and the culture conditions were then restored (Escobar, 2010; Uzarski et al., 2017). 224 The MCF-7 cells were seeded in a 96-well culture plate at a density of 15,000/200 $\mu \mathrm{L}$ for $24 \mathrm{~h}$. 225 Then, a $7 \mathrm{~mm}$ diameter circle containing approximately $16 \mu \mathrm{M}$ of TMX was added to each well 226 with $200 \mu \mathrm{L}$ the culture medium for 1-6 days, in duplicate. Every day, a plate was taken from the 227 incubator and the culture medium was removed; the wells were washed with $200 \mu \mathrm{L} \mathrm{PBS}$, and 228 fresh serum-free medium with $4.4 \mu \mathrm{M}$ resazurin was added, followed by further incubation under 229

230

231

232

233

234

235

236

237 For PBMCs assays, 15,000 cells $/ 200 \mu \mathrm{L}$ were placed in 96-well plates after $24 \mathrm{~h}$ culture and 238 incubated with the PCL-P and PCL-TMX nanofibers, for 24 hours. The plates were then 239 the same initial conditions. After 4, 6, and $24 \mathrm{~h}$, absorbance was measured at the emission wavelength of $595 \mathrm{~nm}$ and excitation wavelength of $535 \mathrm{~nm}$ using a spectrophotometer (Cytation 3 (Borra et al., 2009; Uzarski et al., 2017).

An experiment with free tamoxifen was made, MCF-7 cells were cultured with concentrations of free TMX between $(0-20 \mu \mathrm{M})$, an effect similar with viability percentage to PCL-TMX, was observed with concentrations between 13 and $20 \mu \mathrm{M}$ (see Supplementary figure). centrifuged at $2000 \mathrm{rpm}$ for $5 \mathrm{~min}$, and the medium was replaced with PB-MAX containing 4.4 
240

241

242

243

244

245

246

247

248

249

250

251

252

253

254

255

256

257

258

259

260

261

262

263

264

265

266

267

268

269

270

271

272

273

274

275

276

277

278

279

$\mathrm{mM}$ resazurin, followed by further incubation under the same conditions. After $4 \mathrm{~h}, 6 \mathrm{~h}, 24 \mathrm{~h}, 30 \mathrm{~h}$ and $48 \mathrm{~h}$ the absorbance was measured the same way as with MCF-7 cells lines.

\section{Statistical Analysis}

The results were organized by treatment: PCL-P, PCL-TMX and without nanofiber and by numbers of resorufin measurements according to cell type. The normality test Shapiro-Wilk was applied, then the treatments were compared using Student's t test for unpaired variables: MCF7+PCL-P vs. MCF-7+PCL-TMX, MCF-7+PCL-P vs. MCF-7 without nanofiber, MCF-7+PCLTMX vs. MCF-7 without nanofiber and PBMCs+PCL-P vs. PBMCs+PCL-TMX, PBMCs+PCL$\mathrm{P}$ vs. PBMCs without nanofiber, PBMCs +PCL-TMX vs. PBMCs without nanofiber). Here we found that the PCL-TMX treatment reduced the percentage viability of MCF-7, and the difference was statistically significant in all measurements $(\mathrm{p} \leq 0.05)$. One day after PCL-P treatment of MCF-7 cells, the percentage of viability increases slightly and it is statistically significant only in first day at $4 \mathrm{~h}(\mathrm{p}=0.0160)$ and on the sixth day at $24 \mathrm{~h}(\mathrm{p}=0.0317)$, in the latter case, a clone of MCF-7 with a higher proliferation rate probably emerged. PCL-P induced an increase in the percentage of viability of PBMCs on the first day of treatment, even above the cells without treatment, while PCL-TMX reduced it however, applying the Student's $t$ test the differences were not significant in the PCL-P treatments, but they were significant for the PCL-TMX at $4 \mathrm{~h} p=0.005$ and $6 \mathrm{~h} \mathrm{p}=0.0243$.

Also, ANOVA was applied to three treatments for each cell type (MCF-7+PCL-P vs. MCF7+PCLTMX vs. MCF-7 without nanofiber and PBMCs +PCL-P vs. PBMCs+PCL-TMX vs. PBMCs without nanofiber). All treatments showed statistically significant differences, but this test does not discriminate between groups. Additionally, BONFERRONI test was used to compare each treatment with no nanofiber addition (MCF-7+PCL-P vs MCF-7 without nanofiber, MCF7+PCLTMX vs MCF-7 without nanofiber and PBMCs+PCL-P vs PBMCs without nanofiber, PBMCs+PCL-TMX vs. PBMCs without nanofiber). This showed that PCL-P increases the percentage of viability in a statistically significant way except for the $6 \mathrm{~h}$ data. On the other hand, PCL-TMX decreases this value and only in a statistically significant way for the measurement taken at $24 \mathrm{~h}$.

\section{Results and Discussion}

\section{Physicochemical Characterization}

SEM showed that all PCL-P and PCL-TMX nanofibers were uniaxial, non-porous, and distributed randomly. The incorporation of TMX altered the nanofiber morphology and diameter (see Fig. 1). The PCL-P nanofibers displayed a bimodal diameter distribution, whereas that of the PCL-TMX nanofibers was modal. The largest average diameters were $484 \pm 168 \mathrm{~nm}$ for PCL-P nanofibers 
280

281

282

283

284

285

286

287

288

289

290

291

292

293

294

295

296

297

298

299

300

301

302

303

304

305

306

307

308

309

310

311

312

313

314

315

316

317

318

319

and $400 \pm 236 \mathrm{~nm}$ for PCL-TMX nanofibers. The PCL-P nanofiber diameters were comparable to those reported previously (Katsogiannis, Vladisavljević \& Georgiadou, 2015), and the reduction of the average diameter with TMX incorporation is consistent with previous reports that drug or particle incorporation reduces PCL nanofiber diameters (Zamani et al., 2010; Aristilde et al., 2010; Monteiro et al., 2017; Alavarse et al., 2017; Pinzón-García et al., 2017).

Figure 1. The morphology and diameter distribution of PCL nanofibers showed in micrographs, and histograms corresponding of PCL nanofibers SEM micrographs of a) PCL-P, b) PCL-TMX. Histograms of the diameter of nanofibers of c) PCL-P, d) PCL-TMX.

The FTIR-ATR spectra of TMX and the PCL-P and PCL-TMX nanofibers are shown in Fig. 2. TMX showed a band of intensity at $3229 \mathrm{~cm}^{-1}$ due to the $\mathrm{O}-\mathrm{H}$ from alcohol and phenolic groups. The most characteristic TMX bands were observed: the $\mathrm{C}=\mathrm{O}$ band at $1627 \mathrm{~cm}^{-1}$, the $\mathrm{N}-\mathrm{H}$ band at $1575 \mathrm{~cm}^{-1}$, the $\mathrm{C}=\mathrm{C}$ stretching band (reflecting aromatic ring vibrations) at $1453 \mathrm{~cm}^{-1}$, the double amino $\mathrm{C}-\mathrm{N}$ stretching bands at $1227 \mathrm{~cm}^{-1}$, and the phenolic $\mathrm{C}-\mathrm{O}$ stretching band at 1174 $\mathrm{cm}^{-1}$ (Aristilde et al., 2010; dos Santos Ferreira da Silva et al., 2015). For the PCL-P nanofiber, characteristic infrared bands were observed at $1720 \mathrm{~cm}^{-1}(\mathrm{C}=\mathrm{O}$ carbonyl stretching $), 1240 \mathrm{~cm}^{-1}$ (asymmetrical C-O-C stretching), $1157 \mathrm{~cm}^{-1}$ (symmetrical C-O-C stretching), $2945 \mathrm{~cm}^{-1}$ (asymmetrical $\mathrm{CH}_{2}$ stretching), and $2868 \mathrm{~cm}^{-1}$ (symmetrical $\mathrm{CH}_{2}$ stretching) (Elzein et al., 2004; Gomes et al., 2008). For the PCL-TMX nanofibers, the TMX absorption peaks were not observed, likely due to the small quantity of TMX in them and stretching overlap with adsorption bands of the PCL polymer (Liebenberg et al., 1999; Khalf \& Madihally, 2017).

Figure 2. FTIR spectra of TMX, PCL-P, and PCL-TMX nanofibers.

Fig. 3 shows the XRD patterns of TMX and the PCL-P and PCL-TMX nanofibers. TMX showed low-intensity peaks due to its polycrystalline structure; the main peaks were at $2 \theta=8.5^{\circ}, 9.3^{\circ}$, $10.6^{\circ}, 17.0^{\circ}, 21.1^{\circ}$, and $23.0^{\circ}$ (Liebenberg et al., 1999; Thangadurai et al., 2005; Toro $\mathrm{R}$ et al., 2007). All PCL-P nanofibers showed two characteristic peaks at $2 \theta=21.25^{\circ}$ and $23.55^{\circ}$, attributed to (110) and (200) PCL semicrystalline lattice planes (Baji et al., 2007; Wang, Guo \& Cheng, 2008; Kim et al., 2012). No characteristic TMX peak was detected in the PCL-TMX nanofiber pattern. These results can be explained by the lack of time for the polymers and other compounds to crystallize and form organized structures during electrospinning, which is a very rapid method of polymer fiber preparation (Wei et al., 2010). 
320

321

322

323

324

325

326

327

328

329

330

331

332

333

334

335

336

337

338

339

340

341

342

343

344

345

346

347

348

349

350

351

352

353

354

355

356

357 358

Figure 3. XRD patterns of (a) TMX, (b) PCL-P, (c) PCL-TMX

Fig. 4 shows the TG and DTG curves of TMX and nanofibers. These curves for free TMX showed that three events of mass loss occurred at temperatures of up to $600^{\circ} \mathrm{C}$. The first event corresponds to $7.4 \%$ mass loss at about $100^{\circ} \mathrm{C}$, attributed to dehydration. The second event occurred in two steps (first between $126^{\circ} \mathrm{C}$ and $200^{\circ} \mathrm{C}$ with $20 \%$ mass loss, and second between $200^{\circ} \mathrm{C}$ and $280^{\circ} \mathrm{C}$ with $50 \%$ mass loss, also observed on the DTG curve), and the third event occurred between $500^{\circ} \mathrm{C}$ and $600^{\circ} \mathrm{C}$, with $94 \%$ mass loss. These events can be attributed to the oxidative decomposition of TMX and the remaining carbonaceous matter (dos Santos Ferreira da Silva et al., 2015; Cervini et al., 2015). The PCL-TMX nanofiber patterns (red line) were similar to the reported PCL weight loss pattern (black line), which comprises three events of mass loss, the most critical thermal decomposition event starting at about $340^{\circ} \mathrm{C}$ and ending at $470^{\circ} \mathrm{C}$ (Mohamed et al., 2008) with $70 \%$ mass loss for PCL-TMX and with total weight loss for PCL-P at $600^{\circ} \mathrm{C}$. In this way, the PCLTMX nanofibers showed more excellent thermal stability than did the PCL-P nanofibers and free TMX.

Figure 4. a) TG, b) DTG and c) temperature difference curves of TMX, PCL-P, and PCL-TMX

The contact angles of the nanofibers surfaces were measured to assess the wettability and hydrophilicity of the nanofibers. Table 1 shows the contact angles for the PCL nanofibers and PCLTMX nanofibers. The contact angle of the PCL-TMX nanofiber was smaller than that of the PCL-P nanofiber (hydrophobic nature (Madhaiyan et al., 2013; Tiyek et al., 2019)), perhaps due to the highly hydrophilic COO- moiety of citrate TMX on the surface of the former (Huang et al., 2010). Greater nanofiber wettability may improve cell proliferation and biocompatibility (Sharma et al., 2014). In a similar work, the incorporation of 5-FLU, paclitaxel, and other drugs into PCL nanofibers also increased nanofiber hydrophilicity and provided a good release profile (Karuppuswamy et al., 2015; Iqbal et al., 2017).

\section{In Vitro Drug Release}

Profiles of cumulative TMX release from the PCL-TMX nanofibers over $14 \mathrm{~h}$ are shown in Fig. 5. After $12 \mathrm{~h}$, no TMX signal was detected by UV-vis quantification, reflecting complete TMX release. Thus, to evaluate the kinetics (linear fit) of TMX release from the nanofibers, the cumulative release of the drug was considered between $1 \mathrm{~h}$ to $12 \mathrm{~h}$. The large surface areas and three-dimensional open porous structures of nanofibers may reduce the constraint on drug diffusion and release (Seeram Ramakrishna, Zamani \& Molamma P Prabhakaran, 2013). In addition, the greater hydrophilicity of PCL-TMX nanofibers certainly increased TMX release. 
359

360

361

362

363

364

365

366

367

368

369

370

371

372

373

374

375

376

377

378

379

380

381

382

383

384

385

386

387

388

389

390

391

392

393

394

395

396

397

398

Three distinct, sequential stages of TMX release, reflecting different diffusion processes from the PCL matrix, were observed (Fig. 5a), following the literature (Varshosaz et al., 2011; Sohrabi et al., 2013). In the first stage, there was a linear relationship with a very pronounced and moderate slope. A burst effect was seen, with approximately $50 \%$ of the TMX release in the first hour of the experiment (first 6 points). This initial rapid release may have been due to the accumulation of the TMX molecules at or near the PCL nanofiber surfaces during electrospinning, facilitating TMX release into the media (Zamani et al., 2010). The second stage of release occurred between 1 and $4 \mathrm{~h}$; the release rate decreased gradually, resulting in a moderate slope resulting from TMX diffusion through the PCL nanofibers instead of PCL degradation with the release of approximately $70 \%$ of the TMX. The third stage occurred between 4 and $10 \mathrm{~h}$ and involved the most negligible TMX release that reaches more than $87 \%$ of the TMX release. Thus, sustained TMX release from the PCL-TMX nanofibers was observed up to $14 \mathrm{~h}$. These findings are expected for this type of system because an initial burst of drug release is required to promote a local antitumor effect; the initial dose kills most cancerous cells, and the subsequent controlled release prevents tumor cell growth and proliferation (Ma et al., 2011).

Figure 5. a) Release profiles of TMX from PCL-TMX nanofibers in PBS pH 7.4 and b) Higuchi equation to TMX release from PCL-TMX nanofiber (Where $\mathrm{Mt} / \mathrm{M} \infty$ is the fraction of TMX delivery in time $\mathrm{t}$, and $\mathrm{K}$ is release speed constant).

The mechanism of TMX release was evaluated using the Higuchi kinetic model, based on Fickian diffusion mechanism (Nie et al., 2009). The Higuchi model of the TMX release mechanism best fit to the data for the first $8 \mathrm{~h}$ (Fig. 5b). As this model assumes Fickian diffusion, the cumulative percentage of the drug released $(Q)$ was plotted against the square root of time $\left(t^{1 / 2}\right)$, i.e., $Q=K \times$ $t 1 \frac{1}{2}$, where $K$ is the Higuchi rate constant. The results indicated that diffusion along the PCL matrix occurred, and that TMX release was not dominated by polymer erosion, as claimed in previous studies of biodegradable polymers and water-soluble molecules (Luong-Van et al., 2006; Fredenberg et al., 2011).

Other studies of drug-delivery systems for anticancer molecules, such as TMX, have shown sustained release over $10 \mathrm{~h}$ (Guimarães et al., 2015), 6 days (Criado-Gonzalez et al., 2019), 8 days (Liu et al., 2016), 14 days, 25 days (Iqbal et al., 2017), and 35 days, with different release mechanisms and cytotoxicity. Formulations of nanofibers loaded with tetracycline hydrochloride (TCH), an antibiotic in the same group as TMX, have shown good cytocompatibility in normal cells (Qi et al., 2013; Ranjbar-Mohammadi et al., 2016; Alavarse et al., 2017). Similarly, in this study, PCL-P nanofibers showed good biocompatibility, making it a potential candidate for use as a TMX local delivery system. Since the cytotoxic effect was only observed when the PCL-TMX nanofiber was present. 


\section{Cytotoxicity}

All treatments (MCF-7+PCL-P and PCL-TMX, PBMCs+PCL-P and PCL-TMX) showed statistically significant differences (Fig. 6 and Fig. 7) by ANOVA test. In order to discriminate between groups, we used Student's t-test and each treatment was compared against control (PCLTMX vs no nanofiber and PCL-P vs no nanofiber). After, $24 \mathrm{~h}$ PCL-TMX showed more significant cytotoxicity against MCF-7 than did the PCL-P; 20\% $(\mathrm{p}=0.041)$ cell viability was observed on the first day, in contrast to the $100 \%(p=0.049)$ and $127 \%(p=0.016)$ viability observed in untreated cells and those incubated with PCL-P, respectively. After the second day, resazurin metabolism was barely detected in cells incubated with PCL-TMX; those incubated with PCL-P showed a slight decrease in viability.

Figure 6. Percentage of MCF-7 cell viability: cytotoxic effect of PCL-P and PCL-TMX on 15.000 MCF-7 cells was evaluated after 1 to 6 days of exposure. The reduction of resazurin to resorufin was followed at 4, 6, and 24 hours. PCL-TMX statistically significantly reduced the percentage of viability by the ANOVA method in all treatments.

This can be explained because the TMX inhibits MCF-7 proliferation (Niro, Hennebert \& Morfin, 2010), arresting cells in the G0-G1 phases of the cell cycle. It also activates apoptosis via procaspase 8 , followed by events such as an increase in reactive oxygen species and the release of pro-apoptotic factors from the mitochondria. Real-time polymerase chain reaction revealed an increase in FasL mRNA and tumor necrosis factor- $\alpha$, as well as a decrease in mitochondrial transmembrane potential, after TMX treatment. All these changes are related to the activation of apoptosis (Subramani et al., 2014). After 48h of PCL-TMX incubation, a $99 \%(p=0.016)$ reduction in cell viability, representing a significant difference from the other groups, (Supplementary Table S1). On day 6, slight recovery with 2\% viability was observed, possibly reflecting the growth of a treatment-resistant clone. When MCF-7 cells were cultured with concentrations of free TMX in the range of $0-20 \mu \mathrm{M}$, a similar effect on viability percentage to PCL-TMX, was observed with concentrations between 13 and $20 \mu \mathrm{M}$.

Also, TMX drastically reduced the viability of PBMCs obtained from healthy donors, when PCLTMX added to the culture medium, with statistical significance based on the ANOVA method. After the first day of exposure, the viability percentage reached zero at $4 \mathrm{~h}(\mathrm{p}=0.0126)$ and $6 \mathrm{~h}(\mathrm{p}=$ $0.089)$. On the contrary, PCL-P increased in viability to $256 \%$, which shows that this polymer could be activated PBMCs proliferation (Fig. 7). In PBMCs obtained from breast cancer patients, the effect of TMX is different depending on the duration of treatment. For example in a short time, showed no change in cytotoxic activity type natural killer (NK) cells or proliferative response to mitogens after 8 days of TMX treatment (Sheard et al., 1986). This means that TMX does not activate the NK cells from PBMCs nor induce their proliferation. In a similar study involving 612 months of treatment, a reduced number of lymphocytes with suppressive function was observed 
439 (Joensuu, Toivanen \& Nordman, 1986). In patients treated with TMX for 1.5-2 years, a decrease 440 in NK cell activity and increase in response to the concanavalin A mitogen were observed 441 (Mandeville, Ghali \& Chausseau, 1984). This suggests that if TMX is applied locally, unwanted 442 effects on other tissues can be avoided.

443

444

445

446

447

448

449

450

451

452

453

454

455

456

457

458

459

460

461

462

463

464

465

466

467

468

469

470

471

472

473

474

475

476

477

478
Figure 7. Percentage of PBMCs viability: cytotoxic effect of PCL-P and PCL-TMX on cultured 15.000 PBMCs for 24 hours. The reduction of resazurin to resorufin was followed up at 4, 6, 24, 30 and 48 hours. Increase in the percentage of viability was observed with exposure to PCL-P and reduction with PCL-TMX. The level of significance obtained by the ANOVA method is indicated with asterisks, the values are in the supplementary table S1.

For PBMCs obtained from the peripheral blood of patients with breast cancer and treated with TMX or left untreated, the response to concanavalin A can take up to 5 days (Rotstein et al., 1988). In this study, PBMCs obtained from the peripheral blood of a healthy volunteer and cultured in the presence of PHA showed detectable metabolic activity in the resazurin assay until the fourth day of culture (Fig. 7). However, lymphocytes in culture under the stimulation of a mitogen such as PHA are viable for about $72 \mathrm{~h}$. The viability of PBMCs increased almost threefold in the presence of PCL-P and decreased by approximately $99 \%$ with of PCL-TMX. Little is known about the possible activation and proliferation of PBMCs induced by PCL-P, however they have been used to promote tissue healing in order to promote cell migration (Schoenenberger et al., 2020). In further research, it would be interesting to delve into this aspect. Viability reduction by PCL-TMX is consistent with that reported by Oliveira et al (Oliveira, Genari \& Dolder, 2010), who showed cell death due to apoptosis and autophagy in lymphocytes treated with tamoxifen for 24 and $48 \mathrm{~h}$, in a time - dependent manner, although they applied a dose of $20 \mu \mathrm{M}$ while in this study it was 16 $\mu \mathrm{M}$. They conclude that the effect of TMX on lymphocytes is independent of the estrogen receptor (Behjati \& Frank, 2009). Other side effects of TMX are the induction of proliferation in the endometrium, association with liver cancer, increased blood coagulation, retinopathy and corneal opacities formation (Memisoglu-Bilensoy et al., 2005). Among the potential biomedical (drugdelivery) applications of electrospun nanofibers, local postoperative chemotherapy for the prevention of tumor recurrence and metastasis is prominent (Hu et al., 2014). PCL-P is used to administer several types of drugs in the treatment of cancer such as cisplatin, doxycline, curcumin, paclitaxel among others (Malikmammadov et al., 2018), but there are no reports of tamoxifen delivery systems with PCL nanofibers under the conditions described here.

In this study, the PCL-P nanofibers displayed good biocompatibility, and thus potential application for release TMX. Similarly, nanofibers loaded with TCH have shown good cytocompatibility in normal cells (Qi et al., 2013; Ranjbar-Mohammadi et al., 2016; Alavarse et al., 2017). Other TMX release systems using nanoparticles achieve $68 \%$ release in a first hour (Chawla \& Amiji, 2002)

Peer) reviewing PDF | (2020:12:56248:7:0:NEW 14 Aug 2021) 
479 then maintains the release until 24 hours, while nanofibers released up to approximately $50 \%$ of 480 their content in the first time and maintain a sustained release for hours or days, which can give 481 best results. In addition, the destruction of the nanoparticles requires the use of enzymes such as 482 lipases, which can affect the environment of the treated tissue.

483

484

\section{Conclusions}

486

487

488

489

490

491

492

493

494

495

496

497

498

499

500

501

502

503

504

505

506

507

508

509

510

511

512

513

514

515

516

517

518

519

PCL-TMX nanofibers were produced effectively by electrospinning and showed sustained TMX release for up to $14 \mathrm{~h}$. In cell viability assays, they exhibited excellent activity against the MCF-7 cell line. These results suggest that PCL-P nanofibers have potential application as a TMXdelivery local system (PCL-TMX), that could avoid the collateral effects of TMX treatment in other tissues such as endometrium, liver, cornea or cells such as PBMCs. There are no previous reports of PLC-TMX nanofiber releasing systems in the literature.

\section{Acknowledgements}

The authors would like to acknowledge the financial support from the following Brazilian Research agencies: CAPES, FAPEMIG, CNPq and Center of Microscopy at UFMG, and the Universidad del Rosario and MinCIENCIAS Contract: FP44842-07-2018 Code: 122277657905 , supported this work.

\section{References}

Alavarse AC, de Oliveira Silva FW, Colque JT, da Silva VM, Prieto T, Venancio EC, Bonvent J-J. 2017. Tetracycline hydrochloride-loaded electrospun nanofibers mats based on PVA and chitosan for wound dressing. Materials Science and Engineering: C 77:271-281. DOI: 10.1016/j.msec.2017.03.199.

Aristilde L, Marichal C, Miéhé-Brendlé J, Lanson B, Charlet L. 2010. Interactions of Oxytetracycline with a Smectite Clay: A Spectroscopic Study with Molecular Simulations. Environmental Science \& Technology 44:7839-7845. DOI: 10.1021/es102136y.

Baji A, Wong S-C, Liu T, Li T, Srivatsan TS. 2007. Morphological and X-ray diffraction studies of crystalline hydroxyapatite-reinforced polycaprolactone. Journal of Biomedical Materials Research Part B: Applied Biomaterials 81B:343-350. DOI: 10.1002/jbm.b.30671.

Barnes CP, Sell SA, Boland ED, Simpson DG, Bowlin GL. 2007. Nanofiber technology: designing the next generation of tissue engineering scaffolds. Advanced Drug Delivery Reviews 59:1413-1433. DOI: 10.1016/j.addr.2007.04.022.

Basak V, Bahar TE, Emine K, Yelda K, Mine K, Figen S, Rustem N. 2016. Evaluation of cytotoxicity and gelatinases activity in $3 \mathrm{~T} 3$ fibroblast cell by root repair materials. Biotechnology \& Biotechnological Equipment 30:984-990. DOI: 10.1080/13102818.2016.1192960.

Peer] reviewing PDF | (2020:12:56248:7:0:NEW 14 Aug 2021) 
520

521

522

523

524

525

526

527

528

529

530

531

532

533

534

535

536

537

538

539

540

541

542

543

544

545

546

547

548

549

550

551

552

553

554

555

556

557

558

559

560

561

562

563
Behjati S, Frank M. 2009. The Effects of Tamoxifen on Immunity. Current Medicinal Chemistry 16:3076-3080. DOI: 10.2174/092986709788803042.

Caracciolo, Pablo R Cortez Tornello, Fabián Buffa, Florencia Montini Ballarin, Teresita R Cuadrado, Gustavo A Abraham. 2011. Pequeñas fibras grandes aplicaciones. Instituto de Investigaciones en Ciencia y Tecnología de Materiales, INTEMA (UNMDP-Conicet), Mar del Plata, Argentina 20:57-64.

Cervini P, Ambrozini B, Machado LCM, Ferreira APG, Cavalheiro ÉTG. 2015. Thermal behavior and decomposition of oxytetracycline hydrochloride. Journal of Thermal Analysis and Calorimetry 121:347352. DOI: 10.1007/s10973-015-4447-x.

Chawla JS, Amiji MM. 2002. Biodegradable poly(epsilon -caprolactone) nanoparticles for tumor-targeted delivery of tamoxifen. International Journal of Pharmaceutics 249:127-138. DOI: 10.1016/s03785173(02)00483-0.

Criado-Gonzalez M, Fernandez-Gutierrez M, San Roman J, Mijangos C, Hernández R. 2019. Local and controlled release of tamoxifen from multi (layer-by-layer) alginate/chitosan complex systems.

Carbohydrate Polymers 206:428-434. DOI: 10.1016/j.carbpol.2018.11.007.

De Clercq E. 2015. Ebola virus (EBOV) infection: Therapeutic strategies. Biochemical Pharmacology 93:1-10. DOI: 10.1016/j.bcp.2014.11.008.

Dias AM, da Silva FG, Monteiro AP de F, Pinzón-García AD, Sinisterra RD, Cortés ME. 2019. Polycaprolactone nanofibers loaded oxytetracycline hydrochloride and zinc oxide for treatment of periodontal disease. Materials Science and Engineering: C 103:109798. DOI:

10.1016/j.msec.2019.109798.

Donneyong MM, Bykov K, Bosco-Levy P, Dong Y-H, Levin R, Gagne JJ. 2016. Risk of mortality with concomitant use of tamoxifen and selective serotonin reuptake inhibitors: multi-database cohort study. BMJ 354:i5014. DOI: 10.1136/bmj.i5014.

Drăgănescu M, Carmocan C. 2017. Hormone Therapy in Breast Cancer. Chirurgia (Bucharest, Romania: 1990) 112:413-417. DOI: 10.21614/chirurgia.112.4.413.

Duque L, Rodriguez, Lopez. 2013. ELECTROSPINNING: LA ERA DE LAS NANOFIBRAS. Revista Iberoamericana de Polimeros 14:10-27.

Elzein T, Nasser-Eddine M, Delaite C, Bistac S, Dumas P. 2004. FTIR study of polycaprolactone chain organization at interfaces. Journal of Colloid and Interface Science 273:381-387. DOI:

10.1016/j.jcis.2004.02.001.

Escobar L. 2010. Aplicación de un método fluorométrico para evaluar la proliferación celular en líneas celulares tumorales. Vitae 17:173-180.

Peer] reviewing PDF | (2020:12:56248:7:0:NEW 14 Aug 2021) 
564 Fredenberg S, Wahlgren M, Reslow M, Axelsson A. 2011. The mechanisms of drug release in

565 poly(lactic-co-glycolic acid)-based drug delivery systems - A review. International Journal of

566 Pharmaceutics 415:34-52. DOI: 10.1016/j.ijpharm.2011.05.049.

567

568 Gomes ME, Azevedo HS, Moreira AR, Ellä V, Kellomäki M, Reis RL. 2008. Starch-

569

570

poly( $\varepsilon$-caprolactone) and starch-poly(lactic acid) fibre-mesh scaffolds for bone tissue engineering applications: structure, mechanical properties and degradation behaviour. Journal of Tissue Engineering

571 and Regenerative Medicine 2:243-252. DOI: 10.1002/term.89.

572

573

Group (EBCTCG) EBCTC. 2011. Relevance of breast cancer hormone receptors and other factors to the

574 efficacy of adjuvant tamoxifen: patient-level meta-analysis of randomised trials. The Lancet 378:771-

575 784. DOI: 10.1016/S0140-6736(11)60993-8.

576

577 Guimarães PPG, Oliveira MF, Gomes ADM, Gontijo SML, Cortés ME, Campos PP, Viana CTR,

578 Andrade SP, Sinisterra RD. 2015. PLGA nanofibers improves the antitumoral effect of daunorubicin.

579 Colloids and Surfaces B: Biointerfaces 136:248-255. DOI: 10.1016/j.colsurfb.2015.09.005.

580

581 Hong JH, Ha KS, Jung YH, Won HS, An HJ, Lee GJ, Kang D, Park JC, Park S, Byun JH, Suh YJ, Kim

582 JS, Park WC, Jung SS, Park IY, Chung S-M, Woo IS. 2016. Clinical Features of Male Breast Cancer:

583 Experiences from Seven Institutions Over 20 Years. Cancer Research and Treatment 48:1389-1398.

584

585

586 DOI: 10.4143/crt.2015.410.

587

588

589

590

591

592

593

594

595

Hu X, Liu S, Zhou G, Huang Y, Xie Z, Jing X. 2014. Electrospinning of polymeric nanofibers for drug delivery applications. Journal of Controlled Release 185:12-21. DOI: 10.1016/j.jconrel.2014.04.018.

Huang FL, Wang QQ, Wei QF, Gao WD, Shou HY, Jiang SD. 2010. Dynamic wettability and contact angles of poly(vinylidene fluoride) nanofiber membranes grafted with acrylic acid. Express Polymer Letters 4:551-558. DOI: 10.3144/expresspolymlett.2010.69.

Cancer Today-Globocan. 2018. Available at http://gco.iarc.fr/today/home (accessed April 28, 2021). Iqbal S, Rashid MohammadH, Arbab AliS, Khan M. 2017. Encapsulation of Anticancer Drugs (5-

596

597

598 Fluorouracil and Paclitaxel) into Polycaprolactone (PCL) Nanofibers and In Vitro Testing for Sustained and Targeted Therapy. Journal of Biomedical Nanotechnology 13:355-366. DOI: 10.1166/jbn.2017.2353.

599

600

601 Joensuu H, Toivanen A, Nordman E. 1986. Effect of tamoxifen on immune functions. Cancer Treatment 602 Reports 70:381-382.

603

604 Johnston S, Basik M, Hegg R, Lausoontornsiri W, Grzeda L, Clemons M, Dreosti L, Mann H, Stuart M, 605 Cristofanilli M. 2016. Inhibition of EGFR, HER2, and HER3 signaling with AZD8931 in combination 606 with anastrozole as an anticancer approach: Phase II randomized study in women with endocrine-therapy- 
607 naïve advanced breast cancer. Breast Cancer Research and Treatment 160:91-99. DOI: 10.1007/s10549-

608 016-3979-5.

609

610 Joshi D, Garg T, Goyal AK, Rath G. 2016. Advanced drug delivery approaches against periodontitis.

611 Drug Delivery 23:363-377. DOI: 10.3109/10717544.2014.935531.

612

613 Karn A, Jha AK, Shrestha S, Acharya B, Poudel S, Bhandari RB. 2010. Tamoxifen for breast cancer.

614 JNMA; journal of the Nepal Medical Association 49:62-67.

615

616 Karuppuswamy P, Reddy Venugopal J, Navaneethan B, Luwang Laiva A, Ramakrishna S. 2015.

617 Polycaprolactone nanofibers for the controlled release of tetracycline hydrochloride. Materials Letters

618 141:180-186. DOI: 10.1016/j.matlet.2014.11.044.

619

620 Katsogiannis KAG, Vladisavljević GT, Georgiadou S. 2015. Porous electrospun polycaprolactone (PCL)

621 fibres by phase separation. European Polymer Journal 69:284-295. DOI:

622 10.1016/j.eurpolymj.2015.01.028.

623

624

Kedjouar B, de Medina P, Oulad-Abdelghani M, Payre B, Silvente-Poirot S, Favre G, Faye J, Poirot M.

625 2004. Molecular characterization of the microsomal tamoxifen binding site. JOURNAL OF BIOLOGICAL

626

627

628 CHEMISTRY 279:34048-34048-34061. DOI: 10.1074/jbc.M405230200.

629

Khalf A, Madihally SV. 2017. Modeling the permeability of multiaxial electrospun poly(e-caprolactone)gelatin hybrid fibers for controlled doxycycline release. Materials Science and Engineering: C 76:161-

630 170. DOI: 10.1016/j.msec.2017.03.093.

631

632 Kim Y-J, Park MR, Kim MS, Kwon OH. 2012. Polyphenol-loaded polycaprolactone nanofibers for 633 effective growth inhibition of human cancer cells. Materials Chemistry and Physics 133:674-680. DOI:

634 10.1016/j.matchemphys.2012.01.050.

635

636

637

Laurence J, Cooke H, Sikder S. 1990. Effect of tamoxifen on regulation of viral replication and human

638 immunodeficiency virus (HIV) long terminal repeat-directed transcription in cells chronically infected with HIV-1. Blood 75:696-703. DOI: 10.1182/blood.V75.3.696.696.

639

640

Li S, Cui Z, Li D, Yue G, Liu J, Ding H, Gao S, Zhao Y, Wang N, Zhao Y. 2019. Hierarchically

641 structured electrospinning nanofibers for catalysis and energy storage. Composites Communications 13:1-

642 11. DOI: $10.1016 /$ j.coco.2019.01.008.

643

644 Liebenberg W, de Villiers MM, Wurster DE, Swanepoel E, Dekker TG, Lötter AP. 1999. The Effect of 645 Polymorphism on Powder Compaction and Dissolution Properties of Chemically Equivalent

646 Oxytetracycline Hydrochloride Powders. Drug Development and Industrial Pharmacy 25:1027-1033.

647 DOI: 10.1081/DDC-100102265.

648

649 Liu W, Wang Y, Yao J, Shao Z, Chen X. 2016. Tamoxifen-loaded silk fibroin electrospun fibers.

650 Materials Letters 178:31-34. DOI: 10.1016/j.matlet.2016.04.177. 
651

652

653

654

655

656

657

658

659

660

661

662

663

664

665

666

667

668

669

670

671

672

673

674

675

676

677

678

679

680

681

682

683

684

685

686

687

688

689

690

691

692

693

Luong-Van E, Grøndahl L, Chua KN, Leong KW, Nurcombe V, Cool SM. 2006. Controlled release of heparin from poly( $\varepsilon$-caprolactone) electrospun fibers. Biomaterials 27:2042-2050. DOI: 10.1016/j.biomaterials.2005.10.028.

Ma G, Liu Y, Peng C, Fang D, He B, Nie J. 2011. Paclitaxel loaded electrospun porous nanofibers as mat potential application for chemotherapy against prostate cancer. Carbohydrate Polymers 86:505-512. DOI: 10.1016/j.carbpol.2011.04.082.

Madhaiyan K, Sridhar R, Sundarrajan S, Venugopal JR, Ramakrishna S. 2013. Vitamin B12 loaded polycaprolactone nanofibers: A novel transdermal route for the water soluble energy supplement delivery. International Journal of Pharmaceutics 444:70-76. DOI: 10.1016/j.ijpharm.2013.01.040.

Malikmammadov E, Tanir TE, Kiziltay A, Hasirci V, Hasirci N. 2018. PCL and PCL-based materials in biomedical applications. Journal of Biomaterials Science, Polymer Edition 29:863-893. DOI: 10.1080/09205063.2017.1394711.

Mandeville R, Ghali SS, Chausseau J-P. 1984. In vitro stimulation of human NK activity by an estrogen antagonist (tamoxifen). European Journal of Cancer and Clinical Oncology 20:983-985. DOI: 10.1016/0277-5379(84)90174-3.

Mandlekar S, Kong A-NT. 2001. Mechanisms of tamoxifen-induced apoptosis. Apoptosis 6:469-469-477. DOI: 10.1023/A:1012437607881.

Medina P, Favre G, Poirot M. 2004. Multiple Targeting by the Antitumor Drug Tamoxifen: A StructureActivity Study. Current Medicinal Chemistry-Anti-Cancer Agents 4:491-508. DOI: 10.2174/1568011043352696.

Memisoglu-Bilensoy E, Vural I, Bochot A, Renoir JM, Duchene D, Hincal AA. 2005. Tamoxifen citrate loaded amphiphilic $\beta$-cyclodextrin nanoparticles: In vitro characterization and cytotoxicity. Journal of Controlled Release 104:489-496. DOI: 10.1016/j.jconrel.2005.03.006.

Mochane MJ, Motsoeneng TS, Sadiku ER, Mokhena TC, Sefadi JS. 2019. Morphology and Properties of Electrospun PCL and Its Composites for Medical Applications: A Mini Review. Applied Sciences 9:2205. DOI: 10.3390/app9112205.

Mohamed A, Finkenstadt VL, Gordon SH, Biresaw G, Palmquist DE, Rayas-Duarte P. 2008. Thermal properties of PCL/gluten bioblends characterized by TGA, DSC, SEM, and infrared-PAS. Journal of Applied Polymer Science 110:3256-3266. DOI: 10.1002/app.28914.

Monteiro APF, Caminhas LD, Ardisson JD, Paniago R, Cortés ME, Sinisterra RD. 2017. Magnetic nanoparticles coated with cyclodextrins and citrate for irinotecan delivery. Carbohydrate Polymers 163:1-9. DOI: 10.1016/j.carbpol.2016.11.091.

Peer) reviewing PDF | (2020:12:56248:7:0:NEW 14 Aug 2021) 
694 Nie H-L, Ma Z-H, Fan Z-X, Branford-White CJ, Ning X, Zhu L-M, Han J. 2009. Polyacrylonitrile fibers 695 efficiently loaded with tamoxifen citrate using wet-spinning from co-dissolving solution. International 696 Journal of Pharmaceutics 373:4-9. DOI: 10.1016/j.ijpharm.2009.03.022.

697

698

699

700

701

702

703

704

705

706

707

708

709

710

711

712

713

714

715

716

717

718

719

720

721

722

723

724

725

726

727

728

729

730

731

732

733

734

735
Niro S, Hennebert O, Morfin R. 2010. New insights into the protective effects of DHEA1). Hormone Molecular Biology \& Clinical Investigation 4:489-489-498. DOI: 10.1515/HMBCI.2010.050.

Oliveira NFP de, Genari SC, Dolder H. 2010. Cell death induced by tamoxifen in human blood lymphocytes cultivated in vitro - doi: 10.4025/actascibiolsci.v32i4.7015. Acta Scientiarum. Biological Sciences 32:415-421. DOI: 10.4025/actascibiolsci.v32i4.7015.

Pinzón-García AD, Cassini-Vieira P, Ribeiro CC, de Matos Jensen CE, Barcelos LS, Cortes ME, Sinisterra RD. 2017. Efficient cutaneous wound healing using bixin-loaded PCL nanofibers in diabetic mice: Efficient Cutaneous Wound Healing. Journal of Biomedical Materials Research Part B: Applied Biomaterials 105:1938-1949. DOI: 10.1002/jbm.b.33724.

Qi R, Guo R, Zheng F, Liu H, Yu J, Shi X. 2013. Controlled release and antibacterial activity of antibiotic-loaded electrospun halloysite/poly(lactic-co-glycolic acid) composite nanofibers. Colloids and Surfaces B: Biointerfaces 110:148-155. DOI: 10.1016/j.colsurfb.2013.04.036.

Ramírez-Agudelo R, Scheuermann K, Gala-García A, Monteiro APF, Pinzón-García AD, Cortés ME, Sinisterra RD. 2018. Hybrid nanofibers based on poly-caprolactone/gelatin/hydroxyapatite nanoparticlesloaded Doxycycline: Effective anti-tumoral and antibacterial activity. Materials Science and Engineering: C 83:25-34. DOI: 10.1016/j.msec.2017.08.012.

Ranjbar-Mohammadi M, Zamani M, Prabhakaran MP, Bahrami SH, Ramakrishna S. 2016. Electrospinning of PLGA/gum tragacanth nanofibers containing tetracycline hydrochloride for periodontal regeneration. Materials Science and Engineering: C 58:521-531. DOI: 10.1016/j.msec.2015.08.066.

Robinson E, Rubin D, Mekori T, Segal R, Pollack S. 1993. In vivo modulation of natural killer cell activity by tamoxifen in patients with bilateral primary breast cancer. Cancer immunology, immunotherapy: CII 37:209-212. DOI: 10.1007/BF01525437.

Rogina A. 2014. Electrospinning process: Versatile preparation method for biodegradable and natural polymers and biocomposite systems applied in tissue engineering and drug delivery. Applied Surface Science 296:221-230. DOI: 10.1016/j.apsusc.2014.01.098.

Rotstein S, Blomgren H, Petrini B, Wasserman J, von Stedingk LV. 1988. Influence of adjuvant tamoxifen on blood lymphocytes. Breast Cancer Research and Treatment 12:75-79. DOI: 10.1007/BF01805743.

Peer) reviewing PDF | (2020:12:56248:7:0:NEW 14 Aug 2021) 
736

737

738

739

740

741

742

743

744

745

746

747

748

749

750

751

752

753

754

755

756

757

758

759

760

761

762

763

764

765

766

767

768

769

770

771

772

773

774

775

776

777

778
Salami S, Karami-Tehrani F. 2003. Biochemical studies of apoptosis induced by tamoxifen in estrogen receptor positive and negative breast cancer cell lines. Clinical Biochemistry 36:247-253. DOI:

10.1016/S0009-9120(03)00007-9.

Salman, Falah Hasan Obayes AL-Khikani, Raghdah Maytham Hameed, Younus Jasim Abdullah, Mohanad Kadhim Mirdan Al-Ibraheemi, Atyaf Ali Al-Asadi. 2020. Tamoxifen from chemotherapy to antiviral drug: Possible activity against COVID-19. Biomedical and Biotechnology Research Journal 4:108-108-116. DOI: 10.4103/bbrj.bbrj_53_20.

dos Santos Ferreira da Silva J, López Malo D, Anceski Bataglion G, Nogueira Eberlin M, Machado Ronconi C, Alves Júnior S, de Sá GF. 2015. Adsorption in a Fixed-Bed Column and Stability of the Antibiotic Oxytetracycline Supported on Zn(II)-[2-Methylimidazolate] Frameworks in Aqueous Media. PLOS ONE 10:e128436. DOI: 10.1371/journal.pone.0128436.

Schoenenberger AD, Tempfer H, Lehner C, Egloff J, Mauracher M, Bird A, Widmer J, Maniura-Weber K, Fucentese SF, Traweger A, Silvan U, Snedeker JG. 2020. Macromechanics and polycaprolactone fiber organization drive macrophage polarization and regulate inflammatory activation of tendon in vitro and in vivo. Biomaterials 249:120034. DOI: 10.1016/j.biomaterials.2020.120034.

Seeram Ramakrishna, Zamani M, Molamma P Prabhakaran. 2013. Advances in drug delivery via electrospun and electrosprayed nanomaterials. International Journal of Nanomedicine:2997. DOI: 10.2147/IJN.S43575.

Sestak I, Kealy R, Edwards R, Forbes J, Cuzick J. 2006. Influence of hormone replacement therapy on tamoxifen-induced vasomotor symptoms. Journal of Clinical Oncology: Official Journal of the American Society of Clinical Oncology 24:3991-3996. DOI: 10.1200/JCO.2005.04.3745.

Sharma J, Zhang X, Sarker T, Yan X, Washburn L, Qu H, Guo Z, Kucknoor A, Wei S. 2014. Biocompatible electrospun tactic poly(methyl methacrylate) blend fibers. Polymer 55:3261-3269. DOI: 10.1016/j.polymer.2014.05.028.

Sheard CR, Reilly F, Tee DE, Vergani D, Lowe D, Baum M, Cameron AE. 1986. The effect of adjuvant cyclophosphamide or tamoxifen on the numbers of lymphocytes bearing T cell or NK cell markers. British Journal of Cancer 54:705-709. DOI: 10.1038/bjc.1986.230.

Sohrabi A, Shaibani PM, Etayash H, Kaur K, Thundat T. 2013. Sustained drug release and antibacterial activity of ampicillin incorporated poly(methyl methacrylate)-nylon6 core/shell nanofibers. Polymer 54:2699-2705. DOI: 10.1016/j.polymer.2013.03.046.

Song R, Murphy M, Li C, Ting K, Soo C, Zheng Z. 2018. Current development of biodegradable polymeric materials for biomedical applications. Drug Design, Development and Therapy Volume 12:3117-3145. DOI: 10.2147/DDDT.S165440. 
779 Subramani T, Yeap SK, Ho WY, Ho CL, Omar AR, Aziz SA, Rahman NMohdANAbd, Alitheen NB.

780 2014. Vitamin C suppresses cell death in MCF-7 human breast cancer cells induced by tamoxifen.

781

Journal of Cellular and Molecular Medicine 18:305-313. DOI: 10.1111/jcmm.12188.

782

783 Thangadurai S, Abraham JT, Srivastava AK, Nataraja Moorthy M, Shukla SK, Anjaneyulu Y. 2005. X-

784

Ray Powder Diffraction Patterns for Certain .BETA.-Lactam, Tetracycline and Macrolide Antibiotic

785

786

787 Drugs. Analytical Sciences 21:833-838. DOI: 10.2116/analsci.21.833.

788

Tiyek I, Gunduz A, Yalcinkaya F, Chaloupek J. 2019. Influence of Electrospinning Parameters on the Hydrophilicity of Electrospun Polycaprolactone Nanofibres. Journal of Nanoscience and Nanotechnology

789 19:7251-7260. DOI: 10.1166/jnn.2019.16605.

790

791

Toro R, de Delgado GD, Bahsas A, Delgado JM. 2007. The presence of polymorphism in oxytetracycline hydrochloride shown by X-ray powder diffraction techniques. :563-568.

793

794

Uzarski JS, DiVito MD, Wertheim JA, Miller WM. 2017. Essential design considerations for the resazurin reduction assay to noninvasively quantify cell expansion within perfused extracellular matrix

796

797

798 scaffolds. Biomaterials 129:163-175. DOI: 10.1016/j.biomaterials.2017.02.015.

Varshosaz J, Jannesari M, Morshed M, Zamani M. 2011. Composite poly(vinyl alcohol)/poly(vinyl acetate) electrospun nanofibrous mats as a novel wound dressing matrix for controlled release of drugs.

800 International Journal of Nanomedicine:993. DOI: 10.2147/IJN.S17595.

801

802

Venugopal J, Zhang YZ, Ramakrishna S. 2005. Fabrication of modified and functionalized

803 polycaprolactone nanofibre scaffolds for vascular tissue engineering. Nanotechnology 16:2138-2142.

804 DOI: $10.1088 / 0957-4484 / 16 / 10 / 028$.

805

806

Vitchuli N, Shi Q, Nowak J, Kay K, Caldwell JM, Breidt F, Bourham M, McCord M, Zhang X. 2011.

807 Multifunctional $\mathrm{ZnO} /$ Nylon 6 nanofiber mats by an electrospinning-electrospraying hybrid process for

808 use in protective applications. Science and Technology of Advanced Materials 12:055004. DOI:

809 10.1088/1468-6996/12/5/055004.

810

811 Vyas SP, Sihorkar V, Mishra V. 2000. Controlled and targeted drug delivery strategies towards

812 intraperiodontal pocket diseases. Journal of Clinical Pharmacy and Therapeutics 25:21-42. DOI:

813 10.1046/j.1365-2710.2000.00261.x.

814

815 Wang S, Guo S, Cheng L. 2008. Disodium norcantharidate loaded poly( $\varepsilon$-caprolactone) microspheres.

816 International Journal of Pharmaceutics 350:130-137. DOI: 10.1016/j.ijpharm.2007.08.030.

817

818 Wei A, Wang J, Wang X, Wei Q, Ge M, Hou D. 2010. Preparation and characterization of the electrospun

819 nanofibers loaded with clarithromycin. Journal of Applied Polymer Science 118:346-352. DOI:

820 10.1002/app.32363.

821 
822 Zamani M, Morshed M, Varshosaz J, Jannesari M. 2010. Controlled release of metronidazole benzoate 823 from poly \&-caprolactone electrospun nanofibers for periodontal diseases. European Journal of 824 Pharmaceutics and Biopharmaceutics 75:179-185. DOI: 10.1016/j.ejpb.2010.02.002. 


\section{Figure 1}

morphology and diameter distribution.

The morphology and diameter distribution of PCL nanofibers showed in micrographs, and histograms corresponding of PCL nanofibers SEM micrographs of a) PCL-P, b) PCL-TMX. Histograms of the diameter of nanofibers of c) PCL-P, d) PCL-TMX.
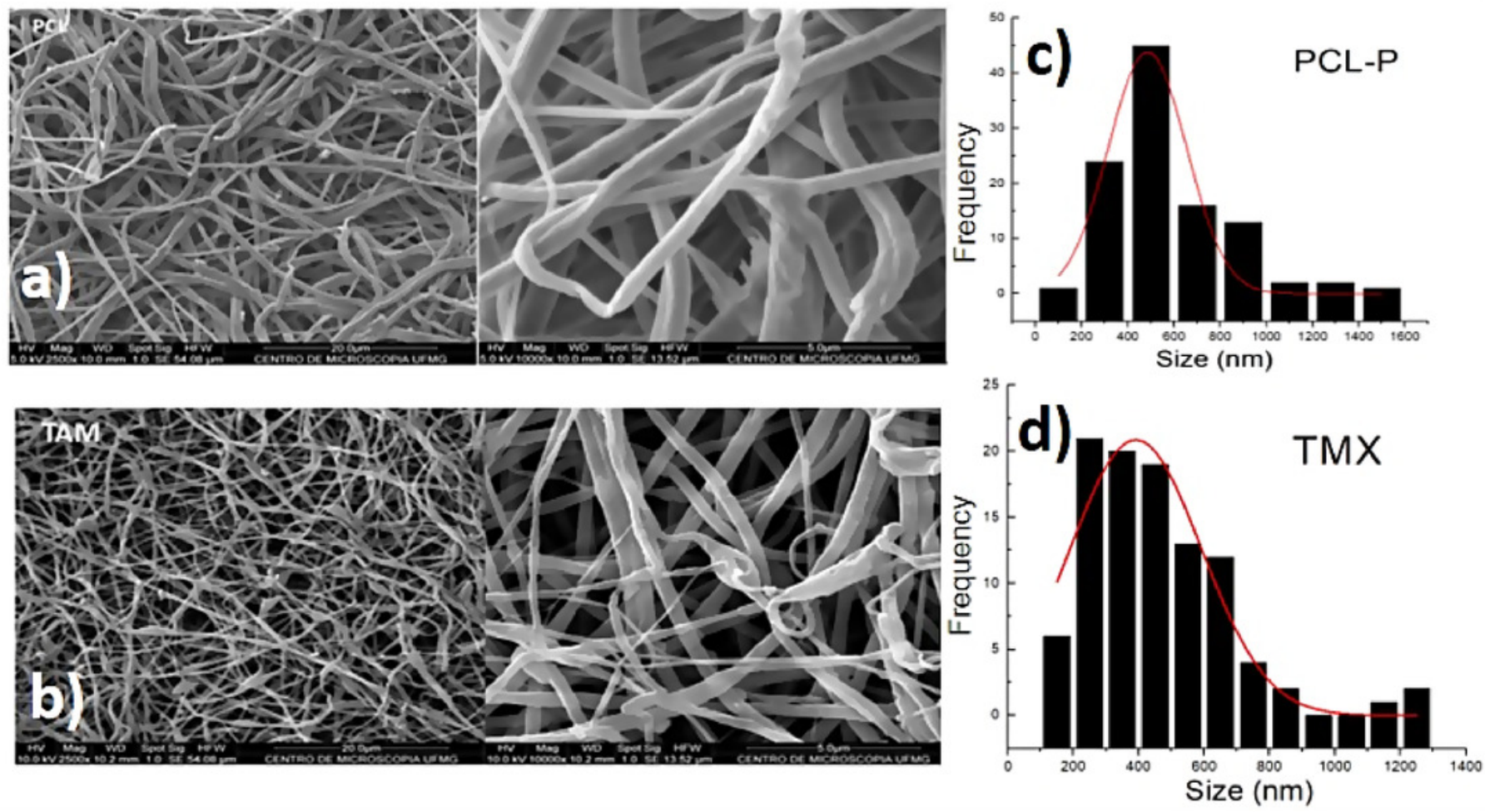
Figure 2

FTIR spectra

FTIR spectra of TMX, PCL-P, and PCL-TMX electrospun nanofibers.

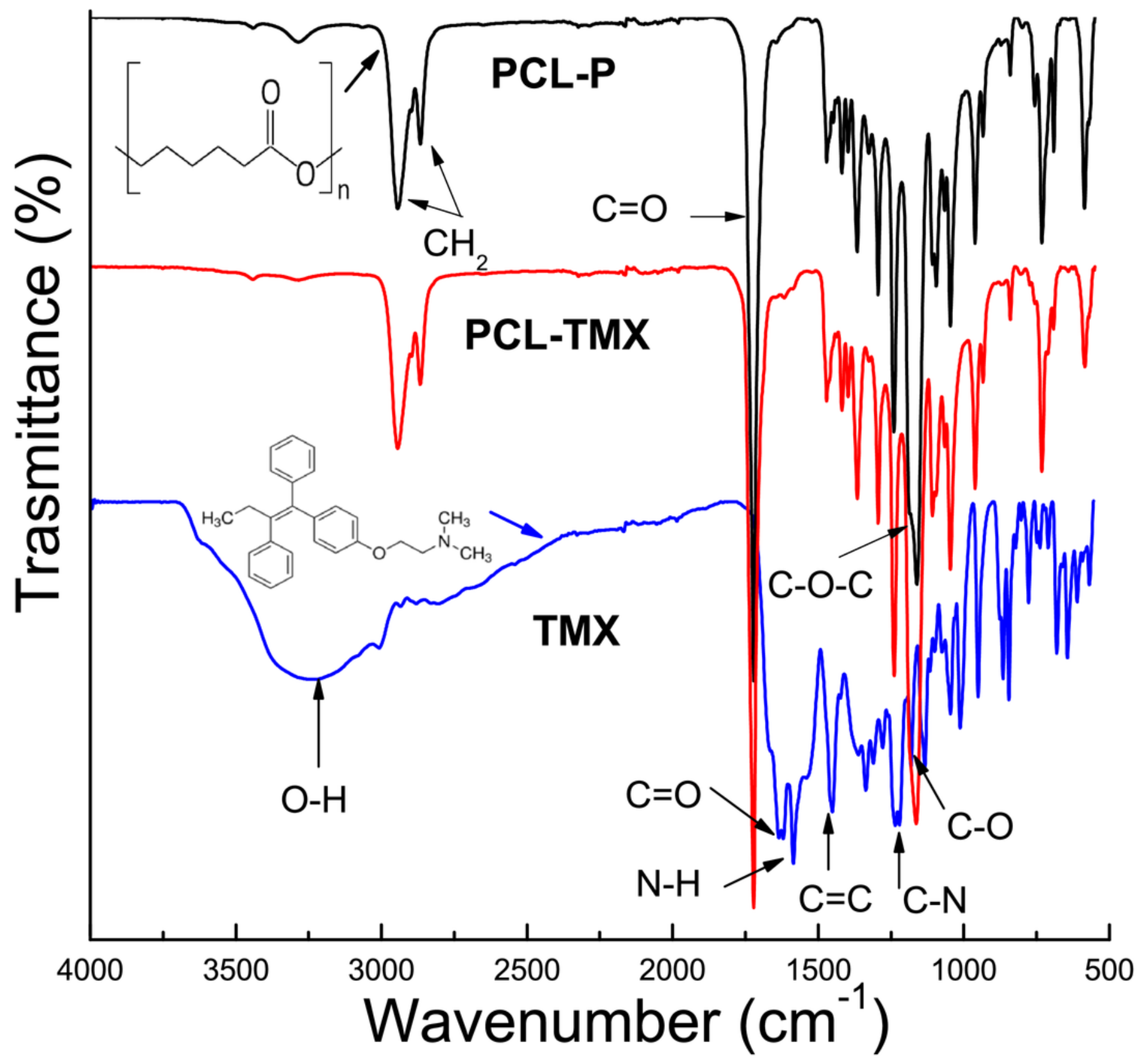


Figure 3

XRD.

XRD patterns of (a) TMX, (b) PCL-P, (c) PCL-TMX

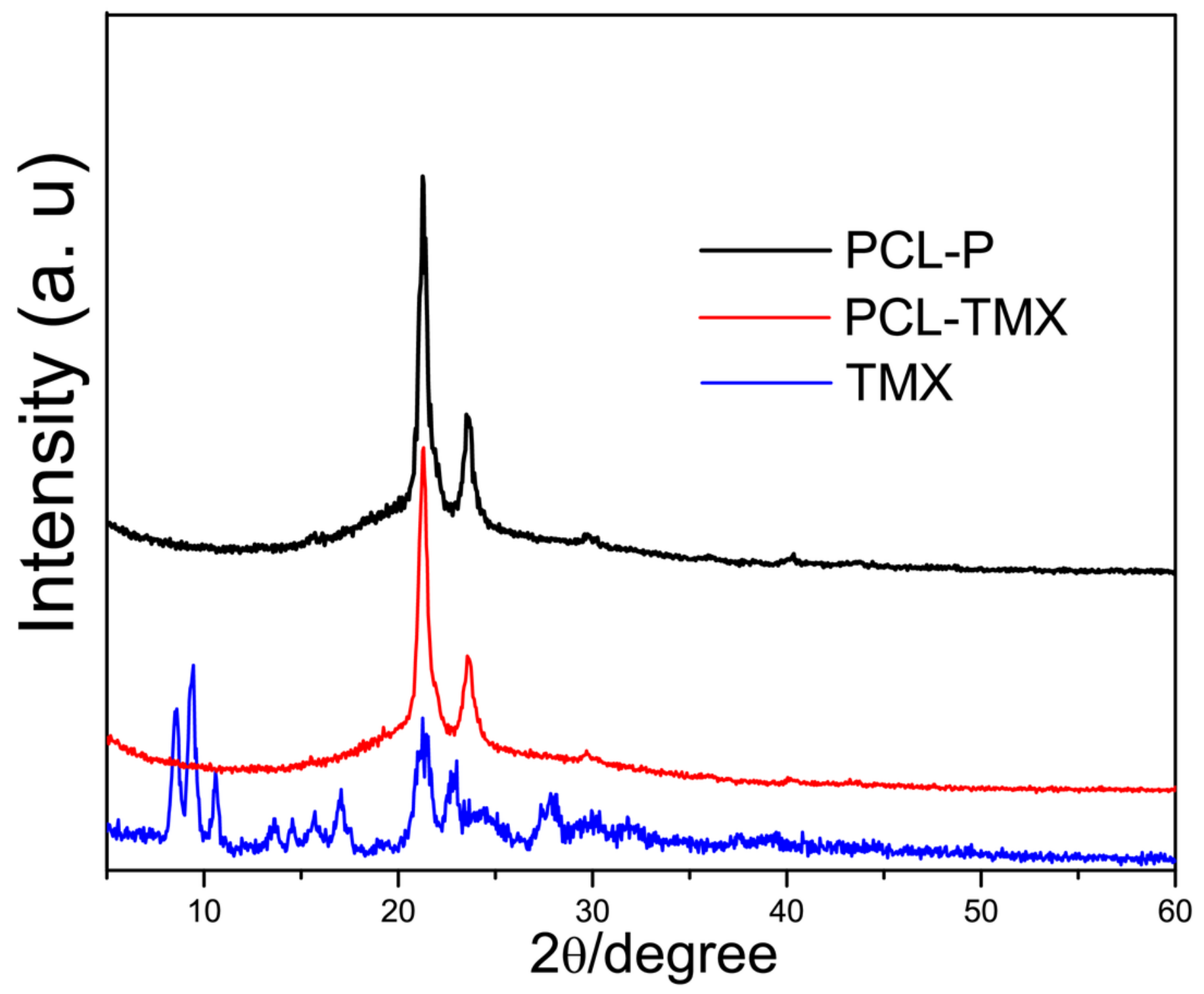


Figure 4

Thermogravimetric analysis.

a) TG, b) DTG and c) temperature difference curves of TMX, PCL-P, and PCL-TMX
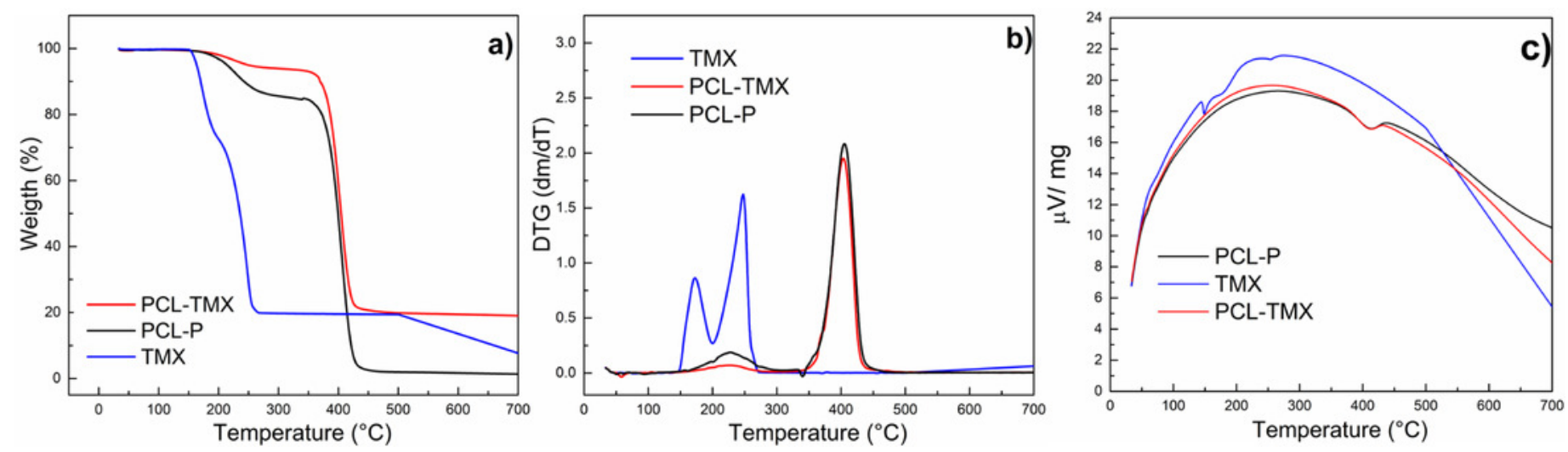
Figure 5

Drug release.

a) Release profiles of TMX from PCL-TMX nanofibers in PBS pH 7.4 and b) Higuchi equation to TMX release from PCL-TMX nanofiber (Where $M_{t} / M_{\infty}$ is the fraction of TMX delivery in time $t$, and $\mathrm{K}$ is release speed constant).
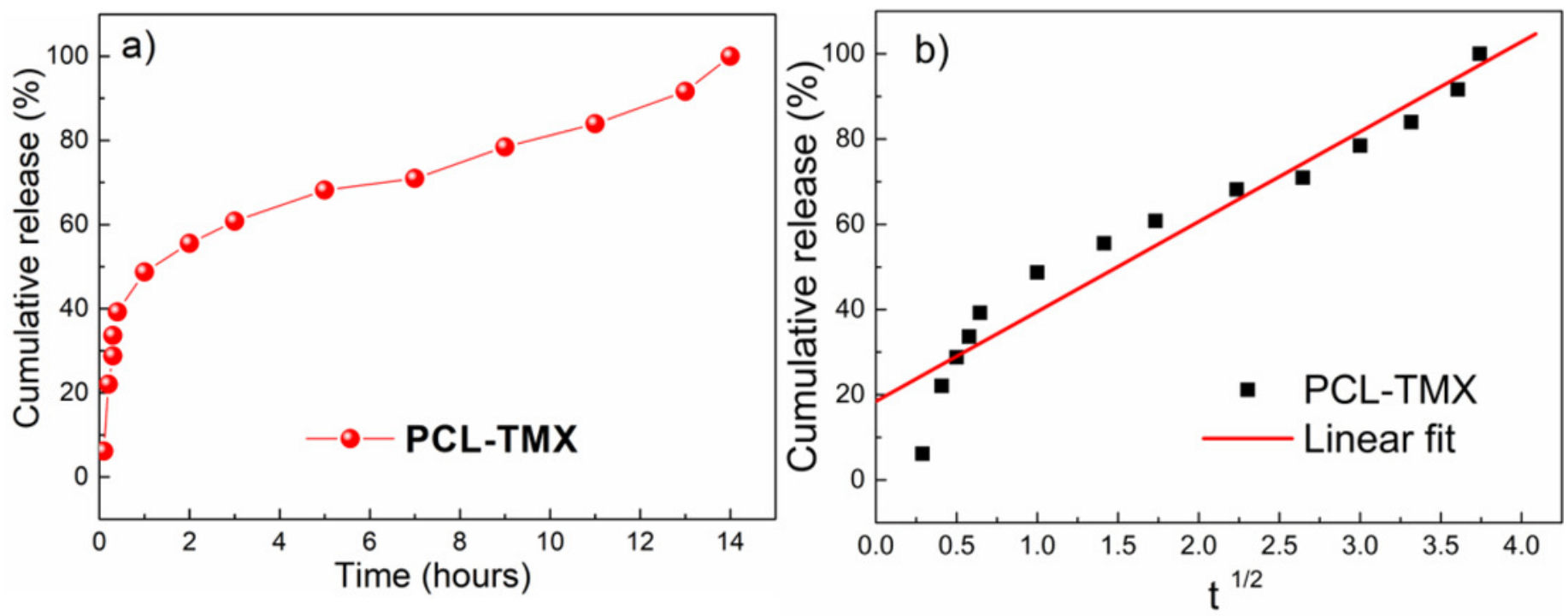
Figure 6

Cytotoxicity assay.

Percentage of MCF-7 cell viability: cytotoxic effect of PCL-P and PCL-TMX on 15.000 MCF-7

cells was evaluated after 1 to 6 days of exposure. The reduction of resazurin to resorufin was followed at 4,6 , and 24 hours. PCL-TMX statistically significantly reduced the percentage of viability by the ANOVA method in all treatments.

Viability MCF-7 + PCL-P and PCL-TMX

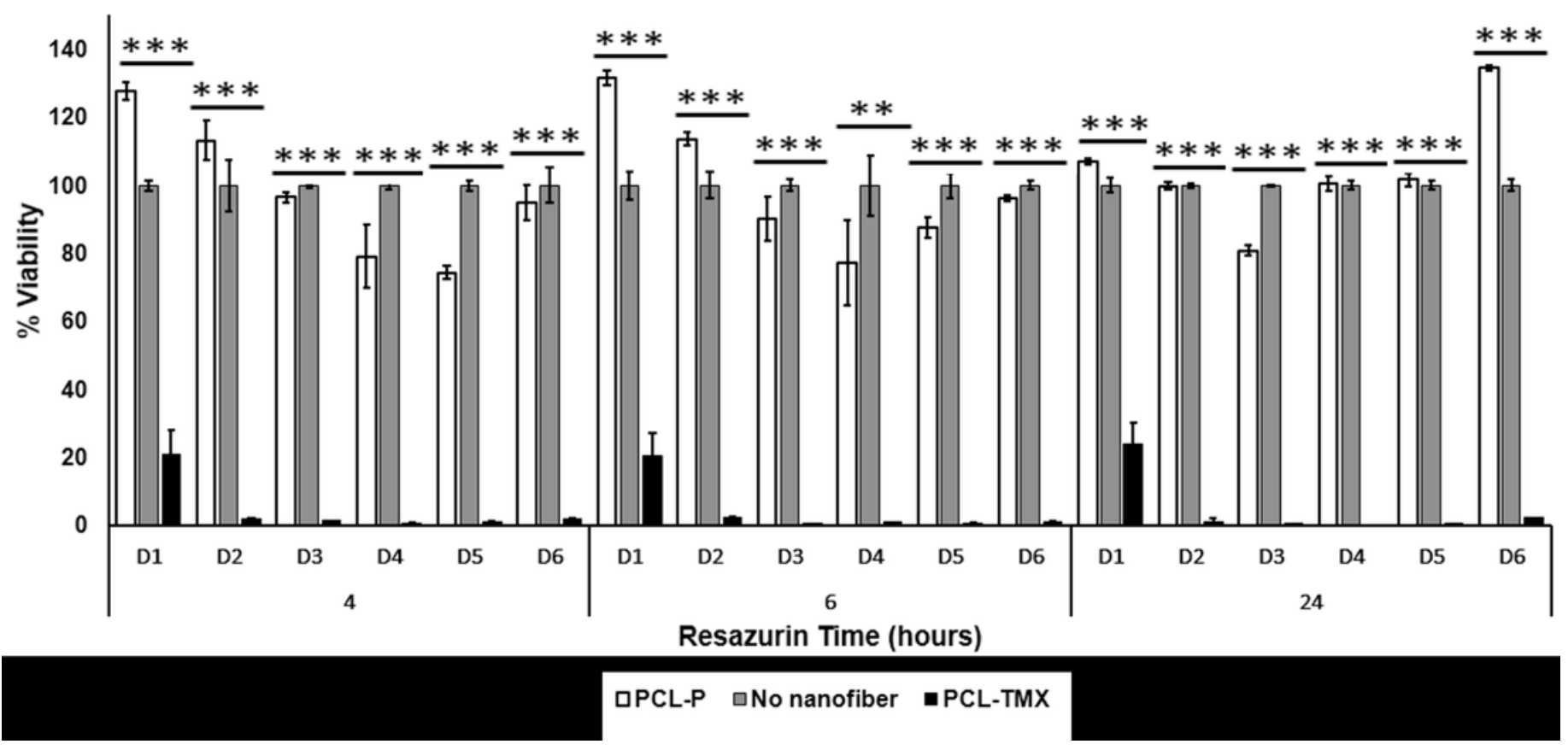


Figure 7

Percentage of PBMCs viability

Percentage of PBMCs viability: cytotoxic effect of PCL-P and PCL-TMX on cultured 15.000 PBMCs for 24 hours. The reduction of resazurin to resorufin was followed up at 4, 6, 24, 30 and 48 hours. Increase in the percentage of viability was observed with exposure to PCL-P and reduction with PCL-TMX. The level of significance obtained by the ANOVA method is indicated with asterisks, the values are in the supplementary table S1.

\section{Viability PBMCs + PCL-P and PCL-TMX}

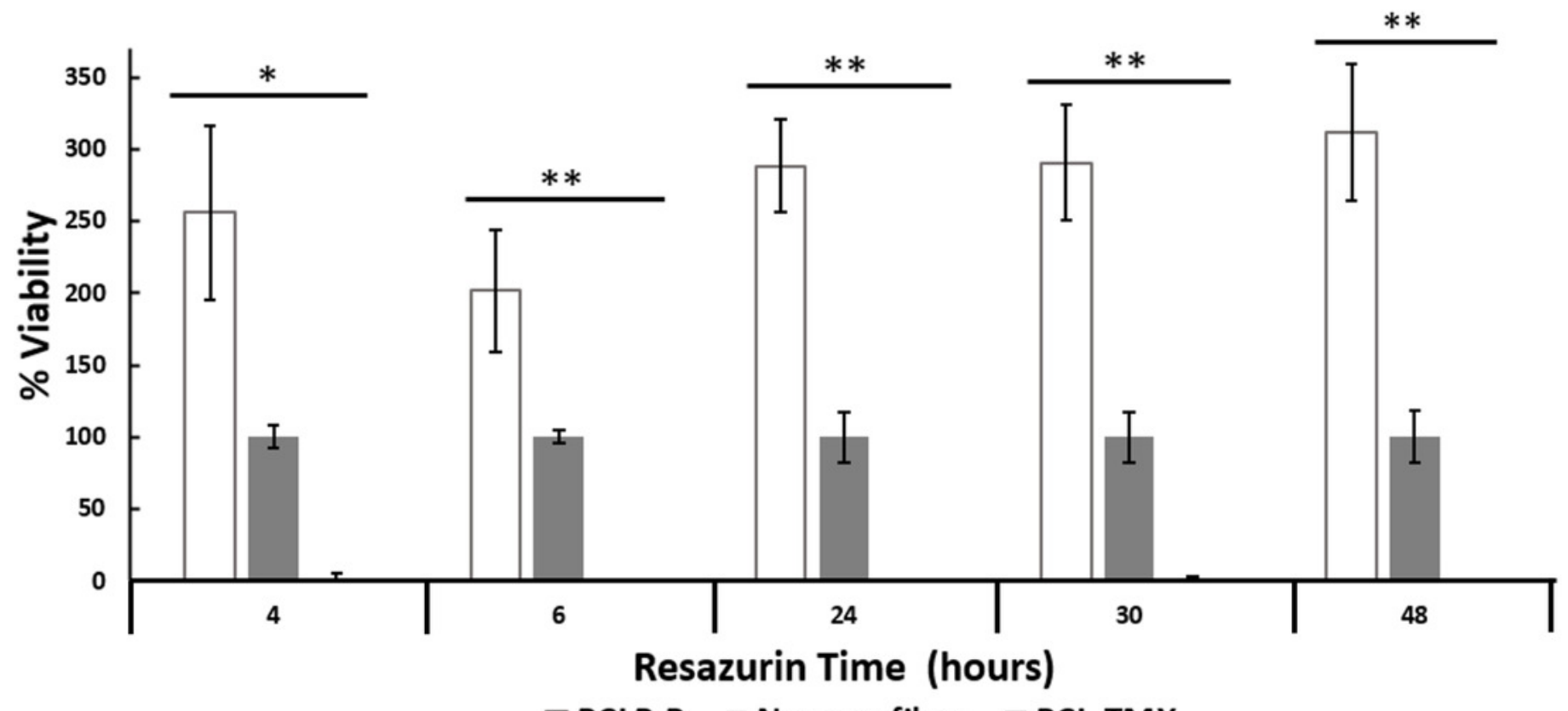

$\square$ PCLP-P $\quad$ No nanofiber $\quad$ PCL-TMX 
Table $\mathbf{1}$ (on next page)

Contact angle.

Contact angle of the PCL nanofibers after 1s and 120s. 


\begin{tabular}{|l|l|l|}
\hline Nanofibers & Time /s & Contact angle / degrees \\
\hline \multirow{2}{*}{ PCL-P } & 1 & 105.75 \\
\cline { 2 - 3 } & 120 & 96.58 \\
\hline \multirow{2}{*}{ PCL-TMX } & 1 & 55.79 \\
\cline { 2 - 3 } & 120 & 32.54 \\
\hline
\end{tabular}

1 